\title{
UNA ÉTICA SECULAR; LA AMISTAD ENTRE LOS ILUSTRADOS
}

\author{
Francisco SANCHEZ-BLANCO PARODY
}

La historia social de la literatura pasa por alto con frecuencia todo aque11 que atañe al descubrimiento y apreciación del ámbito privado e íntimo de la persona en el siglo XVIII, insistiendo en presentar a los ilustrados como hombres sólo preocupados por servir al Estado, menos atentos al bien común que a obedecer las instrucciones del poder y a apuntalar la jerarquía social existente. Los textos que apoyan tal imagen han sido exprimidos al máximo por una crítica que consideraba la Ilustración como el origen de todos los males de la sociedad moderna y del racionalismo que produjo la bomba atómica.

La cuestión que aquí se va a proponer es más bien la de si los ilustrados -junto a la lógica del «bien público» y de la «felicidad de la nación»-inician un discurso reflexivo en torno a una felicidad que ya no es consecuencia, directa o indirecta, de la riqueza nacional, ni depende de la perfección de la organización estatal sino que, por el contrario, exige del Estado que éste deje de inmiscuirse en todos los asuntos y reduzca sus pretensiones en la planificación y control de la vida privada.

Una imagen muy distinta de los principios que mueven la conducta del ilustrado sale a relucir cuando se tiene en cuenta la posición dominante que adquiere la amistad en la moral propuesta por ellos. La reiteración del tema entre los autores de la llustración y su lugar central en la literatura de la época ya fueron señalados por Francisco Aguilar Piñal ${ }^{1}$, Joaquín $\operatorname{Arce}^{2}$ y, más recien-

Cf. "Moratín y Cadalso", en: Revista de Literatura, 42 (1980), 135-150.

2 Cf. La poesía del sigto ilustrado, Madrid, (Alhambra), 1971, pág. 331-341. Sobre este te- 
temente, por David T. Gies. Queda por explicar, primero, como ese principio ético logró imponerse a otras categorías que le disputaban la primacía dentro de los imperativos morales y, segundo, cómo se reorganizan luego en torno a ella la jerarquía de valores que orienta la vida laica.

Que los escritores, especialmente los poetas, en un momento específico del siglo XVIII hayan descubierto la amistad y le hayan dedicadu tanba alención es un fenómeno que pide una explicación, puesto que, si nos fijamos en los tratados de ética que se escribían por aquel tiempo, ésta ocupaba m lugar muy secundario. Andrés Piquer, por ejemplo, trata en su Philosophia moral para la juventud española de los deberes frente a Dios, hacia sí mismo y hacia los otros hombres. En este último apartado se limita a exponer las obligaciones entre príncipe y vasallo, amos y criados, marido y mujer y padres e hijos. A la relación entre iguales no le dedica ningún capítulo especial y sólo se contempla bajo el concepto neotestamentario de «caridad», introduciendo entonces algunas máximas tomadas de autores clásicos.

Este lugar marginal que la amistad ocupa en la ética cristiana es consecuencia de la desconfianza que la tradición ascética medieval muestra hacia el hombre." In exponente de esa mentalidad es Joaquín Calunge y Conzález, antor de un hibro al que puso por título $E l$ más antimo, más lenl y más verdadero amigo del hombre, o la amistad más importante y cierta ${ }^{6}$, en cuya "Adverten" cia al que lo leyerex dice:

* Hijo es este pequeño libro de la experiencia, que me ha enseñado no haber otro más fiel, y verdadero Amigo que Dios; y que su amistad es la cierta y segura, como falaz y expuesta la de los hombres.?

La historia de las ideas debe aclarar el retroceso de esa actitud a religiosa», que previene de apoyarse o buscar consuelo en los hombres, y explicar por qué pierden auturidad aquellas voces que impedían que la anistad pudiera convertirse en el centro de la actitud moral.

\footnotetext{
Ima, pero de una manera muy general, han escrito: Florentina DEL MAR, (seud. de Carmen CONDE), Le amistad en la literatura española, Madrid, 1974, y Pedro LAIN ENTRALGO, Sobre la amistad, Madrid, 1972.

"As's anicitiae, poesía y vida: el ejemplo de Cadalso", en Coloquio Internacional sobre Cadatso: Bolonia, 26-29 de Octubre de 1982, Abano Terme, 1985, pág. 155-171.

Madrid, 1755.

Cf. Thomas VON KEMPEN, De imitatione Christi (1441).

Madrid, 1787.

Ibid., s. p.
} 
Para reconstruir este proceso hay que tener en cuenta la herencia del Humanismo y recordar que la primera reacción contra la decadencia literaria consiste en volver la mirada hacia atrás y releer los autores que rompieron con la cultura escolástica medieval y esbozaron el ideal de la «humanitas». Es un retorno a las formas y contenidos anteriores al Barroco y un programa pedagógico para formar al individuo en todos los saberes humanos y hacerle apto para la vida política en la ciudad terrena.

El método educativo que se empleaba en España fuera de las universidades seguía siendo el humanístico. El conocimiento de las lenguas clásicas y de la historia, introducía al alumno en el estudio del pensamiento moral de los grandes filósofos antiguos. Y al mismo tiempo que tiene lugar la formación moral e intelectual, el contacto con la belleza de expresión educa también su gusto estético. Ejercicios de redacción sobre cuestiones teórico-morales: la vida en la corte y en la aldea, el comunismo de la edad dorada, la primacía de las armas o las letras, entran obligatoriamente en el plan de estudios. Uno de los temas preferidos para esos ejercicios consiste en disertar sobre la amistad ${ }^{8}$, glo- $^{-}$ sando opiniones de Aristóteles, Cicerón y Séneca.

En España, la enseñanza, ya sea mediante tutores privados como en colegiados, sigue vinculada a la clerecía. A sus instituciones acuden los hijos de aristócratas y potentados. No es, por tanto, sorprendente que en tal contexto social los contenidos semánticos de la formación humanística, queden impregnados de cierto espíritu monástico y aristocrático que no tuvieron en tiempos del Renacimiento. Con todo, el retorno al Humanismo introduce elementos que chocan con la vivencia religiosa del Barroco, atenta sólo a las postrimerías del hombre. Ejemplo de esta situación indecisa, entre motivos intramundanos del Humanismo y una ética volcada hacia la trascendencia, es el tratado del monje cisterciense y catedrático de la universidad de Huesca Juan Crisóstomo de Olóriz: Molestias de el trato humano, declaradas con reflexiones politicas y morales, sobre la sociedad del hombre?. Olóriz recoge y comenta extensamente las sentencias de los autores clásicos sobre los aspectos positivos de la comunicación interpersonal, el placer y la necesidad de la amistad, pero, al mismo tiempo, describe la superficialidad y vaciedad de las costumbres sociales como son

* Al igual que este asunto no había ocupado un lugar central en la ética medieval, tampoco tendrá posibilidad de desarrollarse en la sociedad aristocrática y cortesana del Barroco. En cambio, recuérdense los tratados de Leon Battista ALBERTI, I libri della famiglia, Bari 1960; Juan Luis VIVES, "De officio mariti", en: Opera omnia, t. IV, Monfort, 1754; Oliva SABUCO DE NANTES, "Coloquio del conocimiento de sí mismo, título XXVIII", en: Obras, Madrid, 1888.

9 Madrid, 1745. Olóriz cita junto a los moralistas clásicos al iniciador del movimiento humanista, Francesco Petrarca. 
visitas, pésames y banquetes, preguntándose al final, si siendo el hombre, por naturaleza social, tendrá, sin embargo, que huir de los hombres y refugiarse en la soledad para poder encontrarse a sí mismo. Pero esta altemativa no la resuelve claramente.

"¿ Para qué dio compañía Dios al hombre? ¿No fue para que lograse la dulzura del trato humano? ¿Para que en sus iniserias tuviese ese consuelo? Y en fin, ipara que conversase con mutuo amor? Pues reflexione cada uno, si logra estas felicidades con el trato humano, que yo dejaré gustoso al arbitrio de su opiniór que elija su experiencia la comunicación o la soleclad $x^{10}$.

Como monje, Olóriz opta por la soledad, que es, según la ascética tradicional, el «estado de perfeccións. Invalidar de golpe la jerarquía de valores presidida por la vida "en religión* hubiera significado una ruptura brusca con el discurso ético dominante. Pero nuestro fraile tampoco hace una apología unilateral de la «fuga mundi», así como tampoco condena absolutamente el «trato humano», sino que expone ampliamente las ventajas de la amistad. A pesar de que a través de las citas de Aristóteles, Cicerón, Séncca y Petrarca trasluce el esbozo de una ética intramundana, al margen de la estructura sacramental que determina la moral teológica, Olóriz presenta esa doctrina como si fuera plenamente armonizable con la ética «religiosa». Su convicción «humanística» le permite contemplar la cultura pagana como una huella de la revelación a Adán. conservada primordialmente en los textos de los moralistas y filósofos del mundo greco-latíno.

La reflexión sobre la amistad nace, pues, en Espña dentro de un movimiento de reforma literaria implicando, por eso mismo, un cierto rechazo hacia las normas de conducta que imperaban en la sociedad harroca. Fin pl Barrom, como es sabido, la honra y el honor obstaculizaban esencialmente la comunicación personal. Los españoles de esta centuria estaban absesionados por hacer valer su posición en la escala social. Objetiva y subjetivamente, se estiman a sí mismos en cuanto alguien les tributa honores o cuando pueden ostentar públicantente cierta preenumencia. El lugar protucolario quo los está designado en ceremonias cortesanas y en manifestaciones públicas refleja, más allá de la vanidad, la estimación subjetiva de la propia persona y presta, adenás, el pedestal desde el que contacta con otros hombres.

I a comunicación entre iguales ơueda relegada así a un aspecto muy narginal en comparación con el relieve y la importancia que alcanzan las relaciones verticales hacia los de mayor y menor honra. La inquietud interior de los

10 Tbid. pág. 273. 
individuos de esa época, que llega a convertirse en auténtica psicosis, consiste en imaginarse esa fantasmal escala del "señorío» y en exigir a los otros un gesto de reverencia. El «honor» desvirtúa por su propia naturaleza el presupuesto fundamental de la amistad, que es la igualdad. La shonra», además, prescinde hasta cierto punto de la individualidad del otro porque sólo le interesa el signo externo.

Recuperar la «amistad» para la élica es un síntoma claro de la transformación de valores que aporta el pensamiento ilustrado y, también, de la novedad de su actitud moral. Hacia mediados del siglo XVIII se observa, por ejemplo, en España un interés especial por establecer formas de comunicación, paralelas, alternativas y especializadas, al margen de las instituciones tradicionales. La creación en la primera mitad del siglo de las academias científicas y literarias ofrecen un marco a la comunicación intelectual que no es posible dentro de una universidad sometida a la disciplina y al enfrentamiento de las sescuelas». La aparición de las tertulias privadas significa un paso decisivo hacia una forma secularizada de la sociabilidad.

José Clavijo y Fajardo desde su periódico El Pensador se hace eco de las expectativas despertadas por las tertulias:

«[...] tuve algún tiempo en mucha estimación estas Juntas, o Academias Vespertinas, que llaman Tertulias, y deseé con ansia concurrir a ellas, por lo mucho que me las habían alabado. Las consideraba como una Escuela, de que se podía sacar mucho provecho; porque según había oído decir, se formaban los hombres de letras de todas clases, teólogos, juristas, filósofos, poetas, críticos, etcétera, que por medio de una amistosa conversación, se comunicaban mutuamente $[\ldots] *$.

Las tertulias, en cuanto estructura comunicativa, coinciden con las asociaciones gremiales al suponer un impreciso interés común, que ahora proviene de aficiones u ocupaciones similares, y al fomentar el apoyo mutuo. A diferencia de los gremios, las tertulias postergan el aspecto económico, y subrayan decididamente el deseo de hallar un lugar y un clima de comunicación espiritual, que no es posible ni en las academias oficiales ni en las reuniones mundanas.

El modelo masónico de solidaridad e igualdad, inspirado en los antiguos gremios, es difícil de localizar en textos españoles. Sin embargo, aunque en la España Ilustrada, la masonería, en sentido estricto, no fuera más que un fantasma, sus motivos éticos eran de sobra conocidos y aceptados. La efraterni-

${ }^{11}$ Antología de El Pensador. Edición de Sebastián de la NUEZ CABALLERO, Islas Canarias, 1989, pág. 119 s. 
dad» que inspiraba esas agrupaciones sustituía la metáfora de la familia, que conllevaba connotaciones jerárquicas, y reserva mayores alabanzas para la amistad y el compañerismo.

Sin duda, no toda tertulia tuvo su origen en una curiosidad insatisfecha por el rancio saber escolástico. El mero prurito de copiar los salones franceses puso de moda las reuniones pseudointelectiales, de igual modo que el ejemplo italiano de la «Arcadia» y de la Academia dei Quirini en Nápoles influyó para que los poetas se interpelasen entre sí con nombres de pastores. De cualquier manera, el interés humanístico-literario predomina en las nuevas tertulias sobre el utilitario y patriótico. Las Sociedades Económicas, incluso la de Amigos del País Vasco, no son equiparables. En ellas pervive la mentalidad aristocrática y clerical ya que allí las clases privilegiadas pueden airear de algún modo sus sentimientos humanitaríos y demostrar públicamente que se suman al progreso de las ciencias.

Las tertulias, sin reglamentos ni misión oficial, son algo muy diferente a aquellas academias, fundadas por mandato regio para que confirieran una aura de cultura a la majestad del Monarca. Su progresiva especialización literaria las hace también, por otro lado, incompatibles con las convenciones temáticas que impone la galantería en las visitas y reuniones sociales. La tertulia ofrece un claro carácter privado si bien reúne a individuos con gustos estéticos parecidos o con intereses intelectuales relacionados con la actividad profesional. El local de reunión no es un salón aristocrático ni un edificio oficial. Suele ser una casa particular, la celda de un monje o la habitación de un fonda.

El discurso LXXX de $\mathrm{El}$ Censor describe así esta nueva forma de comunicación:

" [...] tengo en mi casa una tertulia que se compone de seis u ocho sujetos de instrucción y buen gusto, y que viene a ser una especie de Academia; prern Academia libre y sin formalidarl. El asunto que la casualidad trae a la conversación arguí es el que se trata con seriedad unas veces, otras jocosamente según es su naturaleza y el humor de qute nos hallamos ${ }^{12}$.

Aun ejerciendo los participantes en ella, por io general, cargos públicas, no tienen inconveniente en hablar y pensas en clara oposición con los contenidos y formas de las ciencia oficial, todavía controlada por una Iglesia inquisitorial y universidad anquilosada, que prohíben la lectura de autores modernos y aboreven las novedades. La tertulia se desmarca de la Universidad y támbién de las instituciones creadas por los Borbones.

1_ T.,IV, pág. 219s. 
En el marco de la tertulia desaparecen, pues, las diferencias aristocráticas y resuenan también las primeras voces a favor del mérito individual y contra los privilegios heredados. La vivencia de la igualdad prepara las reivindicaciones políticas que tendrán lugar en décadas posteriores. Los Discursos mercuriales (1752-1756) de Juan Enrique de Graef dan testimonio de la existencia en España hacia mediados de siglo de un pensamiento antiaristocrático. Las distinciones de linaje o los títulos académicos no resisten la crítica ilustrada. La única condición que requiere la tertulia es la de que entre sus miembros exista confianza y tolerancia, cosa imprescindible para que funcione la comunicación libre de pensamientos y sentimientos.

A partir de 1770, esos círculos inoficiales y espontáneos de comunicación entran en conflicto con la autoridad, lo cual pone de manifiesto un enfrentamiento más radical que en tiempos anteriores entre la minoría ilustrada y el medio social. En Madrid, la tertulia de la Fonda de San Sebastián, en la que se reúnen, entre otros, Cadalso, Femández de Moratín (Nicolás) e Iriarte, no quiere saber nada de los objetivos de interés público que persiguen las academias y, provocadoramente, en sus estatutos imponen la «obligación» de hablar de temas intrascendentes: teatro, toros, amores y versos. Sin embargo, como indicará $E l$ Censor, en ese tipo de reuniones se trataban también asuntos serios, según el caso, siendo lo más importante que la discusión discurriera espontánea y sin las convenciones del protocolo.

Mientras que las academias oficiales servían conscientemente de correa de transmisión a la política «ilustrada del gobierno, los intelectuales de la década de los setenta viven por el contrario al margen de lo oficial, rozando a veces incluso la clandestinidad. En sus reuniones comentan las formas populares de religión y los privilegios de la nobleza con un descaro y mordacidad que desde luego no eran consentidas ni por los eclesiásticos ni por el piadoso Carlos III. Las denuncias y condenas que en estos años recaen sobre los ilustrados son frecuentes. Lo mismo Cadalso, que Iriarte y Olavide serán perseguidos por la justicia en cuanto que sus opiniones y actitudes llegan a oídos de personas ajenas a la tertulia.

Precisamente, los librepensadores o «espíritus fuertes» abandonan los salones aristocráticos para crear pequeños círculos, en los que la naturalidad del trato no se vea cohibida por la jerarquía o por las creencias vigentes, aspirando así a que en ellos sea posible una expresión en que las palabras reflejen lo que realmente cada uno piensa. Al mismo tiempo, al apartarse de lo oficial, no tardan en desenmascarar y satirizar la incapacidad de los personajes de más «honra» en la Corte. 
Los miembros de las tertulias producen abras, que, por lo cáustico de la crítica social, la desfachatez de la sátira política o la falta de respeto hacia jerarquías y costumbres religiosas, sólo pueden ser leídas en reuniones privadas y circular manuscritas entre los conocidos. Muchas poesías burlescas, parodias de kalendarios, testamentos ficticios ${ }^{1.3}$ y los mismos consejos que Nicolás Fernández de Moratín imparte en el Arte de las putas no están destinados al público en general. La tertulia adquiere, en consecuencia, rasgos de clandestinidad y, con ello, fomenta automáticamente la complicidad y solidaridad entre sus miembros. Al peligro de una probable persecución por parte de las autoridades oponen la confianza en la fidelidad y discreción de los amigos. Esos círculos privados favorecen un tipo de comunicación, que por lo subversivo de su contenido no debe trascender al exterior.

El tono jocoso y «volterianos que reina entre los contertulios lo percibimos en las cartas que intercambian miembros de diferentes tertulias. Cadalso eseribe a Moratín y a Iriarte, unas veces, imitando en broma el habla medieval o la jerga de los petimetres, otras, parodiando la terminología escolástica o las frases piadosas de los predicadores y otras, en fin, poniendo rima a las cosas más triviales. El desenfado con que se expresa presupone la discreción y el secreto de sus corresponsales ya que cualquier palabra irrespetuosa frente a la religión, llegada a oídos de los inquisidores, podía acarrear un proceso.

Este tipo paraielo de comunicación y de cultura influye decisivamente en la vida de los literatos españoles del último cuarto de siglo. Lo que Cadalso denominará irónicamente «academia» durante su estancia en Salananca es el grupo de Meléndez, Iglesia y él mismo. En una carta dirigida al «malvado Moratín. da noticias de sus actividades:

* Los sonetos se leerán en la academia de Meléndez y su compañero que juntos me hacen tertulia dos horas todas las noches leyendo naestras obras y las agenas y sujetándose cada uno de los tres a la rigurosa crítica de los otros $\operatorname{dos} x^{14}$.

El espíritu nada piadoso que reina entre ellos se refleja en los temas que prescriben a un neófito que quiere iniciarse en la poesía:

*1.-A las cinco llagas de Sn Francisco. Odas anacreónticas. 2.-A San Antonio teniendo al niño Jesús en cueros sentado en su mano derecha. Idilio anacreóntico. 3.-A San Bernardo echándole leche la Virgen en la boca, como se

13 Cf. Testamento politico del philósapho Marcelo con notas por D. Ramón Estrada Pariente y Valdés. Edición e introducción de Francisco SANCHEZ-BLANCO, Oviedo, 1991.

14 "Obras inéditas de Cadalso", en Reure Hispanique, I (1894), pág. 305. 
ve en los quadros. Sáficos y adónicos. 4.-A San Antón, criando un puerco. Canción pindárica $[\ldots]{ }_{2}^{15}$.

Cuando Cadalso presenta al joven Meléndez a sus amigos de Madrid lo hace en los siguientes términos:

*[... un Letor joven, y vivo de nuestra orden (que se llama Don Juan Meléndez y concurre mucho a mi celda con libertad christiana y religiosa, mozo algo inclinado a los placeres mundanales, a las hembras, al vino, y al campo y sobre todo afecto con demasía a estas cosas modernas; acompañado de muy buena presencia, 20 años no cumplidos, y poco respeto a los prelados) entró el otro día $[\ldots]_{*}^{16}$.

Más adelante, Cadalso narra así las actividades de la singular academia salmantina:

«Extracto de las actas de esta academia. El Viernes Santo propuso un académico (notando lo delgado de la voz de un capon que cantaba aquello de $t i$ bi soli), que conexión phísico-anatómico-harmónica tiene la voz humana con los testículos, o sea partes pudendas. El Sabado Santo después de cantar el gloria y comer pro academia dijo un académico que el grito báquico Evoe! Evoe! significa rigurosamente lo que dicen nuestros borrachos sendas veces al salir de la taberna a saver tarrarral tarrarra! [...] El Lunes de Pascua fué la Academia a la Opera, y un raicmbro de ella notó cierta sensación a la primera cabriola abierta que hizo una bailarina famosa, [...] . Se pregunta qual es la causa phísico-analógico-simpática de este suceso. El Martes de Pascua, la Academia fué a un sermón muy afamado, y antes de concluirse el exordio, roncaban pasmosamente todos y cada uno» ${ }^{17}$.

Estos «académicos» no comulgan ya inocentemente con las convenciones de la vida social y prefieren una cierta automarginación. Ese mismo aislamiento les aporta sensaciones artísticas que están vedadas al gran público. El lema que Cadalso propone a Meléndez: «Odi profanum vulgus», sin embargo, no es expresión de un snobismo elitista, aunque sí del deseo de superar la incultura, superstición, artificialidad y falta de ingenio que caracteriza a la masa.

Fn defensa de la «tertulia» dieciochesca hay que decir que ésta, aún teniendo que guardar discreción, debido a que la institución inquisitorial seguía acechando a los descreídos, no fue nunca algo exclusivista o cerrado. Sus mayores animadores ejercieron una función proselitista e integradora ${ }^{18}$. Desde la

15. Ibid., pág. 317.

16 Ibid., pág. 317 s.

17 Jbid., pág. 327.

18 En Meléndez Valdés, por ejemplo, se observa ya que lo privado es tomado como modelo para la sociedad: "La República de las letras debe serlo de hermanos; en su extensión inmensa to- 
perspectiva del ilustrado había un interés real en lograr nuevos adeptos a la Razón y en admitir nuevos miembros que aumentaran el poder de las Luces.

Teniendo en cuenta la atmósfera especial que reina en la tertulia, nos podemos explicar que una personalidad como la de Cadalso aparezca llena de humor y alegría con sus amigos y que hacia fuera dé la impresión de un hombre sombrio y resentido ${ }^{19}$. Su visión crítica de España y su mismo retraimiento no nacen de un carácter misantrópico, sino del deseo de encontrar un clima de comunicación más íntimo y sencillo donde predomine la inteligencia sobre la vulgaridad. La utopía que él persigue no tiene nada que ver con el ordenamiento perfecto de la sociedad sino con el disfrute de la comunicación sincera e íntima entre los amigos. Si prefiere el retiro y esquivar las frívolas reuniones cortesanas, es por motivos muy distintos a los que, anteriormente, llevaban a negar el mundo y a recluirse en un cenobio. Desprecia las barreras artificiales, creadas por el protocolo y la costumbre, que impiden el trato profundo y sincero y, en oposición al ascetismo tradicional, antepone la compañía de los amigos a la soledad del monje.

Su ideal de vida mundana no coincide tampoco con la sociabilidad que practican majos y petimetres. Cadalso previene incluso contra la moda de lo que él llama irónicamente la «amistad universal» (Carta XI), moderna actitud campechana, opuesta a las ceremonias barrocas, pero igualmente inepta para fomentar el conocimiento personal. Mostrar por sistema familiaridad con todo el mundo, en lugar de conducir a una auténtica * libertad civil» fuera del protocolo, crea nuevas esclavitudes (Carta XXXI). Amistad es, para Cadalso, sinónimo de íntimo y singular $y$, por lo tanto, de algo que no es generalizable.

La sensación de hastío y desarraigo que le produce olservar una sociedad «a la violeta», presuntuosa y hueca, la compensa él reduciendo el espacio de sus amistades. Desengañado de la vida social sí, pero no de los hombres, busca refugio en la vida privada de comunicación con los amigos. De ese giro hacia la intimidad dan testimonio Meléndez y otros contemporáneos ${ }^{20}$. Los propios textos de Cadalso prueban el lugar de excepción que conceden a la amistad.

dos pueden enriguecerse, y si sus niembros conocen un día lo que verdaderanente les conviene, intimantente unidos en trabajos y voluntades, adelantarán más en sus nables empresas y lograrán

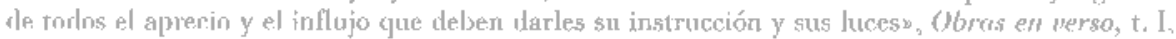
Oviedo, 1981, pág. 68.

19 Nigel GLENDINNING en Vida y obros de Cudalso, Madrid, 1962, subraya milateratmente su misantropía por no conceder la debixla importancia al cliua de comunicación privarla que Cadalso cren a su alrededos.

27. "El me cogí́ en el segurdo año do mis estudios, me abrió los ojos, me enseñó, me inspiró esce noble entusiasmo de la anustad y lo bueno, me formo el juicio [...]", Leopoldo Augusto C.IETO, "Bosquejo histórico crítico de la poesíi castellana en el siglo XVIII", en Poetrs lírices del sigho XFII, T. I, BAE, 61, Madrid, 1952, pág. 107. 
En la carta latina Amico suo jucundo Batylo repite Cadalso la doctrina clásica sobre la amistad tal y como la expresa Aristóteles en el capítulo octavo de la Ética a Nicómaco. La amistad la pueden gozar los hombres "probos» y no los bandidos y delincuentes. Es, además, antídoto contra los males que la naturaleza y la sociedad deparan a los humanos. Cadalso, por su parte, llama la amistad un «don del cielo», no entendiendo con ello algo como la gracia sobrenatural, sino la fortuna y dificultad que presupone el hallarla y experimentarla:

"Quid enim nisi amicitiam probis viris dare potuerunt boni Divi, ut humanae vitae miserandam sortem aliquo ferre modo valeamus? tot inter et tantas palatiorum insidias, castrorum horrores, togae officia, plebis insolentiam, procerum superbiam, fortunae vicissitudinern, mentis insaniam, phisici corporis morbos, caeterasque nostras vix numero continendas, vix nomine distinguendas calamitates, nihil, nihil profecto, miseris hominibus solatium praebet, nisi amicitia, amicitia, inquam, etsi a multis ficta, apud te et alios (pau$\cos$, re vera) invenienda. Et jure apud te inventum a me esse dico pretiosum illud coeli donum, et apud nonnullos quos ego, ut ait Ovidius noster, fraterno dilexi more ${ }^{21}$.

Los poetas ilustrados hablan de amistades concretas, haciendo continua referencia a circunstancias y personajes históricos, lo cual distingue su tratamiento del tema de exposiciones filosóficas abstractas. En esas mismas fechas llega, por ejemplo, de Alemania un espiritualismo intelectual con El espiritu de la amistad de las bellas almas ${ }^{22}$ de C. M. Wieland, obra traducida por Ramón Fernández, seudónimo de Pedro Estala. El título remite a un concepto de «schöne Seele» que no está arraigado en la cultura española. En un lenguaje platonizante, se habla ahí del amor y de la amistad a la manera de una fuerza cósmica que atrae a los hombres de un mismo nivel espiritual y los lleva a gozar de unas alegrías sólo asequibles a las almas selectas.

También de carácter puramente filosófico es la reflexión que motiva el «discurso III» de El Observador, obra del Abate Marchena. Aquí, de acuerdo con la teoría económica liberal, se defiende el amor de sí mismo y parece no dar cabida a la amistad, puesto que en las relaciones humanas priman el individualismo y el materialismo. Siguiendo a Condillac y a Locke, el joven Marchena sostiene provocadoramente que no hemos de buscar en la amistad otra cosa que una sensación y una forma de amarse a sí mismo. El egoísmo, elevado a principio ético, escandaliza a los predicadores y contradice la sensibilidad humanitaria universalista y, sobre todo, filantrópica a nivel privado que inspira a los

"1 "A Don Juan Meléndez Valdés", en Reoue Hispanique, I (1894), pág. 301.

22 Madrid, 1785. Posiblemente la filosofia de la amistad que aparece en esta obra pudo influir en la poesía de Nicasio Alvarez Cienfuegos. 
poetas. El egoísmo de Marchena no excluye, sin embargo, el interés por el bien común y admite la existencia de una decantación civilizada e inteligente del placer que inclina a hacer el bien a los demás. Una "sensibilidad" especial capacita, según él, a los individuos para que incorporen a sus deseos también los ajenos, para sentir, en suma, con los otros. Tal sentimiento está en función de fundamentar la «voluntad general», sobre la que se basa la posibilidad misma de uni ley justa ${ }^{23}, y$, por lo tanto, no describe apenas lo que sucede a nivel de las relaciones privadas. Las intenciones de Marchena al exaltar el amor de sí mismo son de índole política.

Entre los poetas, la experiencia de la tertulia destuorda los límites de la afinidad ideológica, aunque no se pueda negar la importancia que tuvo una fundamental coincidencia en apreciaciones filosóficas, estéticas y políticas para la pervivencia de esas reuniones. Cuando una acalorada disputa, como en los Literatos en cuaresma de Tomás de Iriarte, rompe la armonía del grupo no se pierde la esperanza de reemprender la tertulia sobre la base de la amistad. Los contertulios aprenden, pues, a sentir en comlin, a compartir el mundo interior de los otros, al margen de todo cálculo utilitario y al margen de la animosidad e impersonalidad «lógica» que caracterizaba la discusión académica ${ }^{24}$.

Descle un punto de vista literario podría pensarse que el tema de la amistad nace espontáneamente del subjetivismo propio al género poético. La poesia lírica se presta, sin duda, a tratar el amor y la amistad en tono más íntimo y personal que un tratado de filosofía política o moral. Pero es evidente que lo que parece connatural al género no ha sido tematizado en otras épocas con la intensidad y reiteración que sucede al final de la Ilustración. El afecto personal entre Cadalso y Meléndez, o, entre éste y Jovellanos o, posteriormente, el que une a Blanco White y Lista trasciende el mero dato biográfico que dio origen a una bellas páginas de esos autores. Hay que fijarse en las premisas y consecuencias que lleva consigo el hecho de que el concepto *amistad" pase a primer plano porque, adenás de verbalizar una experiencia, los ilustrados introducen un «discurso» en el que ella desplaza del centro a otros principios y valores éticos. El canto de la amistad llega a tal obsesión entre los ilustrados de finales de siglo que podría muy bien hacer olvidar que éstos se caracterizan generacional-

2) Tantiér Jovellanos relaciona la "sensibilidad" con la responsabilidad social que debe sencir todo hombre de bien y que debe llevar a trabajar por el bien de sus hermanos. Cf. "Epístola 2 " ел Poesícs, Oviedo, 1961, pág. 129-135.

2. Kant dice que existe una amistad basada en un comun "Geschnack" (gusto) o "Gesinnung" (mentalidad) y, además una amistad del sentimento que "[... kann in Deutschen nicht so recht ausgedrükt werden. En sind Gesinnungen der Empfindung und nicht der wirklichen Dienstleistung", Kants Vorlesungen, vol. [V, Berlín, Moral Mrongovius, 1979, pág. 1547 s. 
mente por sus ideas reformadoras de la «res publica». Las razones personales que Cadalso tuviera para fomentar las relaciones de amistad pueden hacer olvidar que el fenómeno, en última instancia, es más colectivo que individual. En cuanto objeto de un «discurso», la amistad desborda el marco biográfico individual para constituirse en motivo central ideológico.

Dentro del género poético, la amistad muestra unos rasgos, que desaparecen automáticamente cuando ella es tematizada en una pieza dramática. El teatro, por estar dirigido a educar al gran público en las virtudes civiles, desarrolla aspectos domésticos y burgueses. La amistad, es decir, el afecto personal sale a relucir a la hora de la elección de estado entre jóvenes o cuando alguien necesita una persona de confianza para realizar un negocio, pero no es considerada ni en su finura psicológica ni en su valor existencial. Es más, queda sometida a los límites de la conveniencia y de la decencia social. En los ejemplos de amistad, propuestos en las comedias -tanto en las traducidas como en las originales españolas-, se procura hacer coincidir el afecto amistoso con la sensatez y utilidad que caracteriza el planteamiento burgués. A este género pertenecen la Escuela de la amistad o el Filósofo enamorado de Juan Pablo Forner y El perfecto amigo ${ }^{26}$ de Gaspar Zavala y Zamora.

Algunas reflexiones sobre la amistad son expuestas con mayor detenimiento en textos en prosa. En sus Cartas marruecas, por ejemplo, Cadalso dedica una (XLVI) a analizar la amistad en la que va más allá de los tratados clásicos. En evidente correspondencia con la moral hedonista subraya no tanto la utilidad de tener amigos como el placer que produce la comunicación con ellos. A diferencia de la moral cristiana, donde la amistad es incluida en el mandamiento genérico del amor al prójimo, con lo que pierde así todo carácter individual, y a diferencia también de aquella moral laica y familiar que propagaron humanistas del Renacimiento, Cadalso estima la relación sentimental entre dos individuos por el puro placer que ella aporta y no por las ventajas y beneficios que pueda proporcionar.

Las Cartas marruecas son interpretadas preferentemente como una meditación sobre el carácter de la nación pero contienen, sobre todo, un auténtico canto a aquel ambiente privado en el que puede germinar la amistad:

25. Madrid, 1796.

26. Barcelona, 1798. Los índices de materias que traen los tomos aparecidos de la Bibliografía de autores españoles del siglo XIIII de F. AGUILAR PIÑAL dan idea de la frecuencia con que se trata el tema de la umistad en el teatro. 
*[...] entre dos corazones rectos la amistad crece con el trato. El recíproco conocimiento de las bellas prendas, que por días se van descubriendo, aumenta la mutua estimación. El consuelo que el hombre bueno recibe viendo crecer el fruto de la bondad de su amigo, le estimula a cultivar más y más la suya propia. Este gozo, que tanto eleva al virtuoso, jamás puede llegar a gozarle, ni aum conocerle, el malvado. [...] Pero dos hombres justos cuando se hallen en alguna situación dichosa, gozan no sólo de su propia dicha, cada uno, sino también de la del otron.

Según esto, la finalidad o utilidad se encuentra en ella misma y no precisa encontrar confirmación en lo que pueda servir para alcanzar fortuna o para incrementar y asegurar ésta. Los amigos son valiosos porque nos alegramos con su sola presencia, porque gozamos la humanidad del otro.

Mientras que en Piquer, la religión y sus principios todavía marcaban límites a la amistad ${ }^{2 a}$, Cadalso ve en ella una dimensión superior a la religión misma ya que gracias a la amistad se podría superar el enfrentamiento entre confesiones y sectas, por ser la amistad un sentimiento que hace pasar a un segundo término los problemas intelectuales. En un pasaje de las Cartas maruecas, cuando el musulmán y el cristiano reflexionan sobre la figura de Santiago Matamoros, la amistad se ofrece como el único vínculo entre los humanos capaz de superar los prejuicios enraizados en costumbres nacionales o en opiniones religiosas:

* Esta conversación entre un moro africano y un cristiano españal es odiosa; pero entre dos hombres racionales de cualquier país o religión puede muy bien tratarse sin entibiar la amistad $\star^{29}$.

Despojada ya de connotaciones especificamente cristianas, la amistad no precisa necesariamente del escenario de una naturaleza idealizada al estilo rousseauniano. Según propio testimonio ${ }^{30}$, Cadalso compuso las Noches lúgubres con ocasión de la muerte de un amigo y rememora en esa obra el proceso que le llevó a estimar la amistad sobre las demás cosas. Tras pintar los males que lleva consigo la condición humana, pasa a reflexionar sobre los diferentes tipos de amor que se dan en el mundo. El amor «natural , como el que los padres sienten por sus hijos, no está libre de resabios egoístas:

27 José CADAISO, Cartas marruecus, Madrid, 1963, cèrta XLVI, pág, 122.

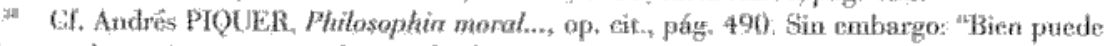

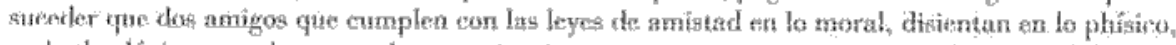
sul lo theoligico, o en las casas de otras ciencias, porque estas no pertenecen a la amistad, la qual

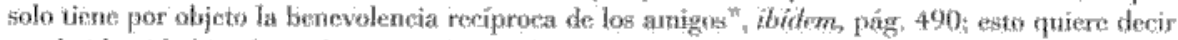
que la identidad intelectual no es sinónimo de amistad y que ésta es posible sin aquélla.

${ }_{20}$ Cartas mamuecas, op cit., carta LXXXVII, pág. 213.

to Cif. ibid, rarta LXVII. 
«Engendran por gusto, crían por obligación, nos educan para que les sirvamos, nos casan para perpetuar sus nombres $n^{37}$.

Tampoco le convence la relación nacida de instintos naturales e institucionalizada en la exclusividad del matrimonio y la familia. La amistad, por el contrario, es un sentimiento ilimitable que inspira el corazón humano y que alcanza su dimensión utópica en la fraternidad que debería unir a toda la humanidad:

« ¡Amigos! ;Amistad! esa virtud sola haría feliz a todo el género humano. Desdichados son los hombres desde el día que la desterraron, o que ella los abandonó. Su falta es el origen de todas las turbulencias de la sociedad ${ }^{32}$.

Meléndez, por su parte, califica reiteradamente la amistad de «santa» y «sagrada» o, lo que es lo mismo, reconoce que es el principio ético por excelencia. Lo que primeramente describía una experiencia particular y una relación privada acaba convirtiéndose en el modelo de las relaciones sociales:
«Ven, alma paz del Cielo, con celestiales visos, y en amistad enlaza los hombres divididos $x^{33}$.

Mientras en Ciadalso domina el tono patético -el amigo es tabla de salvación para los que consideran naufragadas sus ilusiones y sus esperanzas-, en su discípulo Meléndez la amistad se identifica con una alegría vivida en común, la cual hace olvidar las tristezas producidas por desencantos políticos y frustraciones amorosas. Sin desdeñar la función consoladora de la amistad -que junto con el vino «suaviza los más graves trabajos»", el «dulce Batilo» se fija ante todo en los placeres que aporta la relación de amistad en circunstancias cotidianas.

El magisterio que Cadalso ejerció sobre Meléndez Valdés y Jovellanos consiste, pues, en una afirmación decidida de la amistad y no en fomentar una actitud desengañada y agria respecto a su entorno. Sobre todo Meléndez, el estudiante salmantino, con su juventud y alegría, forma un claro contrapunto a la melancolía del militar maduro y desencantado que ya era Cadalso. La actitud despreocupada de aquél en esos años contrasta, por otro lado, con el tono que caracterizaba los informes redactados por los ilustrados que colaboraban con la

\footnotetext{
"José CADALSO, Noches lúgubres, Madrid, 1963, pág. 22.

32 Ibid., pág. 27.

33 Juan MELÉNDEZ VALDÉS, Obras en verso, op. cit., pág. 283.

${ }^{3+}$ Cf. Ibid., letrilla XVI, pág. 273 s.
} 
Monarquía. Meléndez descubre, más allá de las exigencias racionales, el espíritu báquico del que emanan las gratificantes relaciones interpersonales:
*Honor, honor a Baco
el padre [...]
de la amistad sencilla
$[\ldots]$
Ell la jovial franqueza
él lá igualdad inspira
y en los fraternales lazos
Ios corazones liga i. $^{*}$.

Con acento menos dramático, Meléndez repite doctrinas que ya se hallaban en Cadalso: la amistad no equivale a un sentimiento meramente filantrópico o humanitario; a través de ella se descubre la propia interioridad y se penetra en la ajena; y sólo es posible en un ámbito reducido. Su personificación la distingue claramente de una igualdad y fraternidad universales, las cuales son imperativos de la razón.

Lil plantcamiento que Meléndez hace de la aunistad es primeramente empírico y hedonista ${ }^{37}$. I a identifica con el placer de las alegrias compartidas, y le es connatural el sosiego y la constancia, cosa que la distingue de la inestabilidad amorosa. Inclina hacia lo sentimental e inchuso hacia lo curporal.

En los ilıstrados, la fundamentación érica do la amistad no se deduce de la armonía natural. Después del terremoto de 1755 apenas nadie comulga con ell optimismo de T eibniz, segúm el cual el hombre vivé en el mejor de los mundos. l os ilustrados descubren que el orden natural incluye monsiruos y calástrofes por lo que no pucde satisfacer las aspiraciones de armonía y perfección que anidan en el corazón humano. Lna superación del pesimismo no es posible mediante la contemplación del cosmos. Cadalso, por ejemplo, se reconcilia con la existencia al sentir solidaridad y afecto hacia los que sufren un destino semejante al suyo. La desgracia propia pierde importancia al identificarse con la suerte de] amigo y la sensación de caminar juntos transforma esencialmente la desesperación compartida.

Hablar de senequismo estoico, porque la llame «virtud», no parece histó-

". Oda XXXIV, "B Baco", Ibid, pág. 112.

3i. «[...] Cózate en mis ojos, / que mi almas toda está en ellos. / Velos, y hallarás tu imnagen, / que

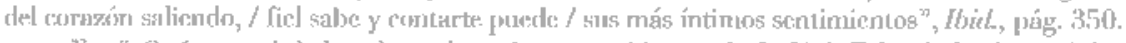

ar "iQué gozo el de las almas / que la amistad ha unido [...]! / ¡Felicidad celeste, / de tordo bien principio!", Ibid., pág. 283. 
ricamente muy esclarecedor. El placer es, para Cadalso, la razón última, pero es un placer que va unido a la misma acción virtuosa.

«El gusto de favorecer a un amigo debe hacerte la vida apreciable, si se conjuran en hacértela odiosa las calamidades que pasas. Nadie es infeliz si puede hacer al otro dichoso ${ }^{38}$.

Como puede verse, estas premisas de la amistad no hacen referencia a la doctrina evangélica ni a la filosofía escolástica. Cadalso ofrece un planteamiento estrictamente intramumdano de la amistad, sin perspectiva escatológica ni transcendente. Dentro del ámbito cerrado del mundo y con una visión desencantada de la condición humana, el placer de la amistad representa la esperanza de dar a la existencia un contenido y un contexto de alegría. En lugar de posponer al más allá la realización de las aspiraciones infinitas de la persona. Cadalso crea con sus amigos ma fictiva sociedad de pastores, una Arcadia, sencilla en sus pretensiones materiales, pero ambiciosa en cuanto a la transparencia espiritual y a la verbalización de la interioridad, abandonando el tosco lenguaje cotidiano y buscando la melodía y el ritmo que mejor exprese los sentimientos.

El mundo poético de las composiciones anacrénticas fascina a los ilustrados. No se trata de la moda pasajera en copiar modelos clásicos. Los "pastores» del siglo XVIII critican el estado actual de la sociedad, rechazan los principios morales por los que ésta rige y renumcian, en fin, a todo «por vivir entre amigos ${ }^{39}$. El bucolismo va más allá del tradicional «menosprecio de corte» porque propone un modelo colectivo y no una fuga individual. El ideal consiste en elevar y profundizar la comunicación y no en limitar la ambición a un núnimo para evitar posibles desengaños y frustraciones.

Aunque lo bucólico pueda reflejar algo del entusiasmo por la agricultura propio del fisiocratismo económico, Cadalso y los otros upastores" no sienten entusiasmo por convertirse en labradores al estilo de Paul et Virginie de Bernardin de Saint Pierte. La Arcadia de los poetas españoles tiene muy poco que ver con la agricultura y sí mucho con una vida de intercambios de sentimientos, al margen de las convenciones sociales.

Los círculos, en tomo a Cadalso y Jovellanos, no se plantean, como ya se ha dicho, la cuestión rle la amistad desde una perspectiva burguesa/utilitaria,

José CADALSO, Noches hígubres, op, cit., pág. 65.

Cf. José CADALsO, "Poesías", en Poetas fíricos del siglo XYIII, BAE 61, Madrid, 1952, pág. 273. 
aceptada sin reparos por representantes del pensamiento tradicional ${ }^{\text {th }}$, aunque coincida con ésta en algunas apreciaciones: la riqueza de dinero, por ejemplo, la consideran un obstáculo para encontrar amigos sinceros. Su fascinación por la Arcadia tampoco radica en una nostalgia del mundo clásico puesto que los "pastores» ilustrados apenas transmiten conceptos e imágenes de la Antigüedad. Sus referencias a la mitología son más bien escasas y triviales. Ante todo, los poetas se retratan a sí mismos, disfrazados o, mejor dicho, despojados de su estrecho e incómodo ropaje civil y cotidiano. La atmósfera sensual y sentimental que ellos respiran carece de connotaciones cortesanas versallescas y remite al ambiente retirado y particular de los amigos.

En el Renacimiento y el Barroco, la utopía pastoril permitió dar a la sensualidad un marco diferente al de la naturaleza humana caída -descrita sombríamente una y otra vez desde los púlpitos-, en el Siglo de las Luces, los nombres de Dalmiro, Jovino, Batílo y Arcadio prestan el camuflaje necesario para establecer una comunicación íntima, inaceptada e impropia en ropaje civil. La posterior sátira de Espronceda contra el «Pastor Clasiquino» es históricamente injusta, pero comprensible en una situación donde la expresión espontánea y libre de la subjetividad ya no es tabú. Al romántico, el disfraz pastoril de la generación anterior parece ya un signo de inautenticidad y de cursilería.

La ficción bucólica de los ilustrados tiene como motivo central la amistad y no el amor heterosexual, Los pastores hablan de sus problemas amorosos, de sus penas y celos, pero se consuelan con los amigos. En Desdenes de Filis; Égloga entre Dalmiro (Cadalso) y Ortelio (José López de Huerta), pastores ${ }^{41}$ encontramos los siguientes versos:

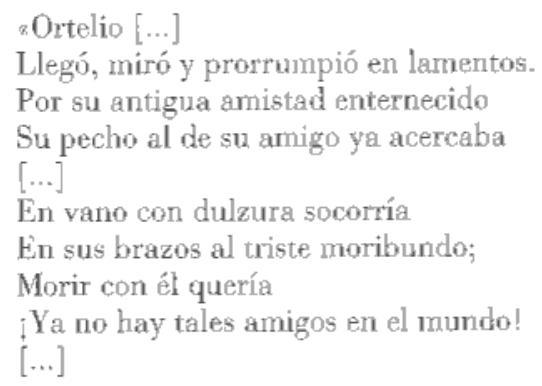

* Bernardino FERNÁNDEZ DE VELAGCO Y PIMENTEL, (duque de Frías), Detoyte de lo discreción, y fácil escuela de la agudeza, que en ramillete texido de ingentosas promptitudes, y moralidades provechosas, con muchos arisos de christiano y politico desengaño, que dividido en ocho capitulos de todas clases de personas y sexos, publica en reconocimiento obsequioso de la curiosidad cortesana, Madrid, 1743.

"José CADALSO, "Poesías", op, cit., pág. 254 s. 
Hasta que quiso el cielo

Que en tal amigo hallara

Consuelo que bastara,

Contándole con queja su quebranto.

En todo el mundo no hay consuelo tanto

Como contar a su leal amigo

El motivo del llanto

Sin arte, sin respeto, sin testigos ${ }^{42}$.

La poesía se nutre del diálogo entre amigos y aun cuando a veces se presenta como una reflexión solitaria o como una entidad abstracta, detrás siempre trasluce la metáfora de la amistad. En la composición en la que Refiere el autor (Cadalso) los motivos que tuvo para aplicarse a la poesía y la calidad de los asuntos que tratará en sus versos escribe:

*Así como se alienta el peregrino

Cuando encuentra con otro en el camino

Y con gusto el piloto al mar se entrega

Si otro con él el mismo mar navega;

Como se alivia el llanto si un amigo

De nuestras desventuras es testigo;

Así los tristes versos que leía

Templaban mi fatal melancolías ${ }^{43}$.

La vivencia de la amistad brinda la ocasión y el motivo para componer versos. La poesía es vehículo y testimonio de contactos personales. Las situaciones serán en gran parte triviales: la despedida, el cumpleaños, la recomendación de un compañero, el envío de obras propias o ajenas. La poesía de finales del siglo XVIII y principios del XIX perdería todo su contenido y resultaría incomprensible si se abstrayera la recíproca relación biográfica y literaria que existe entre los poetas, porque la institución del "grupo», creada por Cadalso para dar marco a la poesía, no desaparece con su persona sino que significa un elemento imprescindible de la creación poética por lo menos hasta los tiempos de José M. Blanco White y Alberto Lista.

Cadalso centra todo su interés en la contemplación de la subjetividad y ve ésta constituida esencialmente por la relación con los otros y no por el autoanálisis narcisista o rousseauniano. Ciertamente, en algunos poetas, la sensibilidad para comprender y compadecer en común degradará en una tendencia a verter lágrimas ruidosas ${ }^{44}$. Pero es conveniente constatar que el descubrimiento de la interioridad entre los ilustrados españoles no llega por las vías del monó-

${ }^{2}$ Ibid., pág. 254 .

* Ibid., pág. 248 .

${ }^{44}$ Cf. José Luis CANO, "Cienfuegos y la amistad", en Clavileño, n. ${ }^{\circ} 34,1955,35-40$. 
logo solitario, sino que surge siempre en forma de una interioridad comunicada a interlocutores históricos. Rousseau, paseante solitario entre árboles y setos, goza en cambio sintiéndose incomprendido y escribe para que, a falta de amigos, los lectores, al menos, perciban la belleza de su alma. Cadalso, por el contrario, habla de alegrías, penas y trabajos compartidos y si alguna belleza merece la pena de ser cantada no es la de un alma rumiante sino la de la amistad vivida. Lus poenas de esta épuca adyuieren todo su significado cuando son leídos junto con las respectivas respuestas de sus destinatarios.

Los illustrados también son conscientes de que la ética de la prosperidad de la nación, del patriotismo y del bien público no satisface todas las aspiraciones del individuo. En los dramas, al rememorar la figura mítica de Guzmán el Bue$n 0^{45}$, exaltan, por un lado, la responsabilidad y el imperativo racional que debe guiar los pasos de quienes ocupan cargos públicos, pero, por otro, ven claramente la tragedia del hombre de Estado cuando éste tiene que elegir entre los sentimientos privados y su función social ${ }^{46}$. En lugar del Estado perfecto, en la mente de los poetas se dibuja una utopía de signo contrario: la del paraíso perdido; paraíso, que ellos se imaginan como una especie de ámbito privado, localizable preferentemente en un especie de vida rústica idealizada. Sin duda, al gobierno de Carlos III le interesaba que los nobles y terratenientes abandonaran la vida ociosa de las ciudades y se preocuparan directamente por los asuntos del campo, pero también es verdad que lo que el poeta Meléndez esboza en la Egloga en alabanza de la vida del campo ${ }^{47}$, ganadora de un concurso oficial, es una utopía de la vida en austeridad y amistad que no responde a los intereses económicos de la política gubernamental.

Si alguna utopía mueve a los últimos ilustrados no es, desde luego, la de la perfecta organización en un Estado totalitario. Más bien ellos se orientan hacia la Aucadia clásica, en la que el trabajo, realizado en un entorno privado, pernite relaciones interpersonales, fuente de la auténtica felicidad. Las mismas reformas económicas con las que ellos comulgan son aquéllas que posibilitau la felicidad privada por encima de la felicidad de la nación. El hier público consistirá, pues, en crear las prenisas para que uquélla pueda desarrollarse. Autonomía económica (propiedad privada), libertad de expresión y tolerancia religiosa serán exigencias políticas posteriores que, de alguna forma, se legitiman porque anteriormente el ámbito privado ha sido idealizado en la utopía de una vida entre amigos.

45. Cf mi articulo: "Transformaciones y [unciones de un mito nacional: Guzuán e] Bueno", en Revista de literatua, n." 100, 1988, 387-422.

tw Cf José CADALSO, Certers mumecas, op. cit., carta LV, págr. 133-135.

${ }^{+7}$ Madrid, 1780. 